\title{
Response of Seed Germination and Seedling Growth to Sand Burial of Two Dominant Perennial Grasses in Mu-Us Sandy Grassland, Semiarid China
}

\author{
Yajuan Zhu, ${ }^{1,2}$ Ming Dong, ${ }^{1}$ and Zhenying Huang ${ }^{1}$
}

\begin{abstract}
Authors are ${ }^{1}$ Research Scientists, State Key Laboratory of Vegetation and Environmental Change, Institute of Botany, Chinese Academy of Sciences, Beijing 100093, People's Republic of China; ${ }^{2}$ Research Scientist, Research Institute of Forestry, Chinese Academy of Forestry, Beijing 100091, People's Republic of China.
\end{abstract}

\begin{abstract}
Sand burial is an important selective pressure for growth, survival, and distribution of sand dune plants. Its effects on seed germination and seedling establishment, however, for different species are quite different. Experiments were conducted in the Mu-Us Sandy Grassland of North China to determine the effects of sand burial on seed germination and seedling growth of dominant perennial grasses Psammochloa villosa (Trin.) Bor and Leymus secalinus (Georgi) Tzvel. Small, medium, and large seeds of $P$. villosa and small and large seeds of L. secalinus were buried at 0-, 1-, 2-, 4-, 6-, and 8-cm depths in sand. P. villosa seed germination and seed dormancy in sand were significantly influenced by sand burial depth but not by seed size, whereas seed germination and seed dormancy of L. secalinus were significantly influenced by both sand burial depth and seed size. Emergence percentages for large seeds were higher than those for smaller seeds, suggesting that larger seeds are ecologically better adapted to dune habitats. Seeds that did not germinate in sand were in enforced dormancy and formed a soil seedbank, which can enhance plant survival on sand dunes. One-week-old and 2-wk-old P. villosa seedlings could tolerate $75 \%$ and $100 \%$ of their shoot height of sand burial, respectively, and the shoot elongation growth was enhanced by the burial stress. Both 1-wkold and 2-wk-old seedlings of L. secalinus only tolerated up to $75 \%$ sand burial. The growth of L. secalinus seedling was inhibited by sand burial due to the decreased biomass and slow shoot elongation. The lack of tolerance of seedlings of this species to total sand burial might restrict its distribution on sand dunes.
\end{abstract}

\section{Resumen}

La presión de la arena es un factor importante para el crecimiento, supervivencia, y distribución de las plantas en dunas de arena. Sus efectos sobre la germinación de la semilla y el establecimiento de plántulas son marcadamente diferentes entre especies. Algunos experimentos se llevaron a cabo en un pastizal arenoso (Mu-Us) del norte de China para determinar los efectos de la presión de la arena sobre la germinación de la semilla y el crecimiento de la plántulas de los zacates perennes Psammochloa villosa (Trin.) Bor y Leymus secalinus (Georgi) Tzvel. Semillas pequeñas, medianas, y grandes de P. villosa y semillas pequeñas y grandes de L. secalinus se enterraron a $0,1,2,4,6$, y $8 \mathrm{~cm}$ de profundidad. La germinación y dormancia de la semilla de $P$. villosa en la arena fue significativamente influenciada por la profundidad de siembra pero no así por el tamaño de la semilla, mientras que la germinación y dormancia de la semilla de L. secalinus recibieron influencia significativa tanto por la profundidad de siembra como por el tamaño de la semilla. Los porcentajes de emergencia para semillas grandes fueron más altos que los que se observaron en semillas pequeñas, sugiriendo que semillas grandes son ecológicamente mejor adaptadas para hábitats de dunas. Las semillas que no germinaron el la arena presentaron un periodo de dormancia obligado formando parte del banco de semillas en el suelo, lo cual puede incrementar la sobrevivencia de las plántulas en las dunas de arena. Plántulas de una o dos semanas de P. villosa toleraron $75 \%$ y $100 \%$ la profundidad de siembra, respectivamente. La elongación del tallo se incrementó por el estrés de la profundidad de siembra. Plántulas de L. secalinus de una y dos semanas sólo toleraron hasta el $75 \%$ de la profundidad de siembra. El crecimiento de plántulas de L. secalinus se inhibió por la profundidad de siembra debido a que decreció la biomasa y disminuyo la elongación de tallos. La falta de tolerancia de las plántulas de esta especie para el total de la profundidad de siembra podría restringir su distribución en las dunas de arena.

Key Words: biomass allocation, germination strategy, sand burial tolerance, seed enforced dormancy, seed size

\section{INTRODUCTION}

This study was supported financially by the National Key Basic Research Special Fund of China (2007CB106802), Key Project of the Chinese Academy of Sciences (KZCX2-XB2-01), the National Natural Science Foundation (30570281, 30872074) of People's Republic of China, and Key State Laboratory of Vegetation and Environmental Change (Vegetation-water Long-term Networked Experiments of China project).

Correspondence: Professor Zhenying Huang, State Key Laboratory of Vegetation and Environmental Change, Institute of Botany, The Chinese Academy of Sciences, Beijing 10093, People's Republic of China

Manuscript received 12 July 2007; manuscript accepted 12 May 2008.
Desertification is the most severe problem in grasslands and sandlands in North China. In the desertified grassland, seed germination and seedling growth are affected by many ecological factors, such as drought, high temperature, sand burial, and sand erosion (Bowers 1996; Maun 1998). In Mu-Us sandy grassland of North China, sand burial is a familiar phenomenon occurring on moving sand dunes. The shoots, seeds, and seedlings of sand dune plants often are buried by sand (Maun 1994, 1998). Thus, plants must tolerate sand 
burial to survive and reproduce in sand dune habitats (Hesp 1991; Huang et al. 2004a, 2004b).

Seed germination and seedling emergence of some species can be improved by moderate sand burial (Maun 1998). However, seed germination and seedling emergence is restricted if seeds are buried too deeply by accumulating sand. The seeds that do not germinate in deep sand are in enforced dormancy and thus are part of a soil seedbank, which benefits long-term survival of the species. These dormant seeds can germinate when their burial depth is decreased by wind erosion (Huang et al. 2004a, 2004b).

Some sand dune plants tolerate total burial, whereas others tolerate partial burial. After an episode of sand burial, seedlings of some grasses transport organic compounds from buried shoots and roots to aboveground shoots; therefore, they can maintain photosynthetic organs and increase the probability of survival (Harris and Davy 1987; Martinez and MorenoCasasola 1996; Brown 1997).

The purpose of our study was to determine differences in the response of seed germination, seedling emergence, and seedling growth to sand burial in the natural habitat between Psammochloa villosa (Trin.) Bor, a dominant perennial grass inhabiting moving sand dunes of North China and Mongolia, and Leymus secalinus (Georgi) Tzvel., a perennial grass inhabiting fixed sand dunes of North China (Ma 1994).

According to our field survey, P. villosa and L. secalinus are clonal grasses and their natural population was dominated by clonal ramets. Previous study indicated clonal growth and clonal integration play an important role in their clonal expansions, such as in supporting the survival of new ramet on sand dunes (Dong 1999; Dong and Alaten 1999). However, sexual reproduction is critical for plants to maintain their genetic diversity and thus is important in their life cycles. Therefore, we hypothesize that sexual reproduction of these two plant species also is important for the development of new genotypes with new adaptations that can contribute to its survival. We expected that these two plant species might develop different seed germination and seedling growth strategy, because they are distributed in different dune habitats of semiarid grassland. To this end, our objectives were to 1) test the effect of moderate burial depth on seed germination and seedling emergence of the two sand dune grasses and 2) determine if their seedlings can tolerate total sand burial, and if so, determine if there is a change in their shoot elongation growth after they are buried. The findings will provide insights to the underlying mechanisms for the spatial distribution of these dominant species in the Mu-Us sandy grassland as well as guidance for conservation and ecological restoration of these sandy grassland ecosystems.

\section{MATERIALS AND METHODS}

\section{Field Site}

During summer of 2004, experiments were carried out in the Ordos Sandland and Grassland Ecological Station of the Institute of Botany, Chinese Academy of Sciences. This ecological station (lat $39^{\circ} 02^{\prime} \mathrm{N}$; long $109^{\circ} 51^{\prime} \mathrm{E}$ ) is located in $\mathrm{Mu}-$ Us sandy grassland, North China at an altitude of $1355 \mathrm{~m}$. The mean annual temperature varies from $5.0^{\circ} \mathrm{C}$ to $8.5^{\circ} \mathrm{C}$ and the mean annual precipitation is $358.5 \mathrm{~mm}$, most of which occurs from June to September.

\section{Seed Collection and Storage}

The natural dispersal units of $P$. villosa and $L$. secalinus were used in these experiments. For P. villosa, the natural dispersal unit is one naked caryopsis. For L. secalinus, the dispersal unit is one palea-enclosed caryopsis. For these experiments, the dispersal units are considered seeds for both species.

Mature seeds of both species were collected in autumn 2003 from plants growing in their natural habitat near the ecological station. Seeds were stored in a cloth bag at $-18^{\circ} \mathrm{C}$ (International Seed Testing Association 1985) in the freezer compartment of a refrigerator. Mean seed mass was tested after some seeds were stored dry at room temperature for 1 mo. Mean $( \pm$ SE) seed masses for $P$. villosa and L. secalinus were $5.51 \pm 0.03 \mathrm{mg}$ $(n=100)$ and $3.49 \pm 0.05 \mathrm{mg}(n=100)$, respectively. Prior to the experiments, seeds of $P$. villosa and L. secalinus were treated by a 4 -wk and 8 -wk cold stratification, respectively, at $5^{\circ} \mathrm{C}$ to break the innate dormancy of freshly matured seeds. After cold stratification, seed germination of $P$. villosa and L. secalinus were about $90 \%$ at $20-30^{\circ} \mathrm{C}$ and $30^{\circ} \mathrm{C}$, respectively, after $14-\mathrm{d}$ incubation in light or darkness.

\section{Effect of Seed Size and Sand Burial on Seed Germination and Seedling Emergence}

Seed germination experiments were conducted in a nonheated greenhouse from 10 June to 9 July 2004. During the experiments, the minimal and maximal air temperature in the greenhouse varied from $19^{\circ} \mathrm{C}$ to $35^{\circ} \mathrm{C}$. Randomly selected seeds were weighed and sorted one by one through the electronic balance $( \pm 0.01 \mathrm{mg})$. For $P$. villosa, seeds were sorted into small $(4.0-4.9 \mathrm{mg}$, mean $=4.45 \pm 0.01 \mathrm{mg})$, medium $(5.0-5.9 \mathrm{mg}$, mean $=5.46 \pm 0.01 \mathrm{mg})$, and large $(6.0-6.9 \mathrm{mg}$, mean $=$ $6.42 \pm 0.01 \mathrm{mg}$ ) sizes. Seeds of $P$. villosa were buried to depths of $0,1,2,4,6$, and $8 \mathrm{~cm}$. For L. secalinus, seeds were sorted into small $(3.0-3.5 \mathrm{mg}$, mean $=3.08 \pm 0.03 \mathrm{mg})$, and large $(3.6-$ $4.0 \mathrm{mg}$, mean $=3.96 \pm 0.03 \mathrm{mg}$ ) sizes and buried at the same depths. Each treatment was determined by the combination of seed size and burial depth. There were eight replicates of 50 seeds for each treatment.

Seeds were buried in sand to the required depth in a plastic pot $(10-\mathrm{cm}$ diameter and $12-\mathrm{cm}$ height). The drainage outlet of the pot was covered with strips of nylon mesh to prevent the loss of sand, while allowing drainage of excess water. The sand in each pot was moistened with $50 \mathrm{~mL}$ of well water. Seedling emergence was monitored daily, and an additional $50 \mathrm{~mL}$ of water was added every $2 \mathrm{~d}$. Because very few seedlings emerged after $20 \mathrm{~d}$ of burial, the experiment was terminated on day 30 when no more seedlings emerged. Then, using a nylon sieve, the sand in each pot was checked carefully for nonemerged seedlings (seeds germinated but the etiolated seedlings did not emerge above the sand surface) and nongerminated seeds. Viability of nongerminated seeds was tested with a $1 \%$ solution of 2, 3, 5-triphenyl-2H-tetrazolium chloride (TTC; Baskin and Baskin 1998). These seeds were soaked in the TTC solution for $24 \mathrm{~h}$ and then were cut with a surgical knife to check the color of the embryo. If the embryo was red, the caryopsis was 
Table 1. Sand burial depth (cm, mean $\pm \mathrm{SE}$ ) for 1-wk-old and 2-wk-old seedlings of Psammochloa villosa and Leymus secalinus.

\begin{tabular}{|c|c|c|c|c|}
\hline \multirow[b]{3}{*}{ Burial ratio } & \multicolumn{4}{|c|}{ Sand burial depth $(\mathrm{cm})$} \\
\hline & \multicolumn{2}{|c|}{ Psammochloa villosa } & \multicolumn{2}{|c|}{ Leymus secalinus } \\
\hline & 1-wk-old & 2-wk-old & 1-wk-old & 2-wk-old \\
\hline $0 \%$ & 0 & 0 & 0 & 0 \\
\hline $25 \%$ & $1.5 \pm 0.1$ & $2.1 \pm 0.2$ & $2.67 \pm 0.2$ & $3.4 \pm 0.2$ \\
\hline $50 \%$ & $3.1 \pm 0.2$ & $4.1 \pm 0.1$ & $5.5 \pm 0.2$ & $6.9 \pm 0.2$ \\
\hline $75 \%$ & $4.2 \pm 0.1$ & $5.6 \pm 0.1$ & $8.4 \pm 0.3$ & $10.2 \pm 0.2$ \\
\hline $100 \%$ & $5.6 \pm 0.1$ & $8.4 \pm 0.2$ & $10.8 \pm 0.2$ & $13.3 \pm 0.1$ \\
\hline
\end{tabular}

considered viable; if not, it was nonviable. Seeds that tested as viable were considered to be in enforced dormancy when buried.

\section{Effect of Sand Burial on Seedling Growth}

Seedling growth experiments were conducted in a nonheated greenhouse from 18 June to 17 July 2004. During the experiments, the minimal and maximal air temperature in the greenhouse varied from $20^{\circ} \mathrm{C}$ to $37^{\circ} \mathrm{C}$.

Seeds of relatively similar size and weight were used in this experiment, and the masses of $P$. villosa and L. secalinus were 5.0-5.9 $\mathrm{mg}$ and 3.3-3.6 mg, respectively. There were 200 pots for each of the two species, and five seeds were buried to a depth of $1 \mathrm{~cm}$ in each pot. Each pot was sprayed with $50 \mathrm{~mL}$ of well water. Seedling emergence was monitored daily, and water was added when necessary to keep the sand moist. After emergence, the first seedling was kept in the pot and the others were discarded, leaving one seedling per pot. Fifty seedlings that emerged on the same day were used in the sand burial experiments. Seedling height was measured to the nearest millimeter before the seedling was buried.

One-week-old and 2-wk-old seedlings of each species were buried in sand to $0 \%, 25 \%, 50 \%, 75 \%$, or $100 \%$ (Table 1) of their mean shoot heights in a nonheated greenhouse from 18 June to 17 July 2004. Different heights of plastic rings were added to the pot; the single seedling remaining was buried to the required depth. The sand was moistened initially with
$50 \mathrm{~mL}$ of well water, and later as required to keep the sand surface moist during the experiment. There were 10 replicates for each burial ratio. The experiment was terminated after $30 \mathrm{~d}$. Then, the seedlings were removed from the pots, washed free of sand, and their total length, shoot length, and root length were measured. After measurement, each seedling was divided into shoot and root, put into a paper bag and dried at $80^{\circ} \mathrm{C}$ for $48 \mathrm{~h}$. An electronic balance (0.1-mg accuracy) was used to weigh the mass of shoot, root, and thus the total seedling. The root:shoot ratio was calculated from the shoot and root masses.

\section{Data Analysis}

Results of seed germination, seed dormancy, and seedling emergence were expressed as $\% \pm \mathrm{SE}$. To ensure the normality of data, the percentages were arcsine square root-transformed; biomass, height, and length of seedlings were log-transformed. Two-way analysis of variance (ANOVA) at the 95\% confidence level was used to examine the main effects of seed size, sand burial depth, and their interactions on seed germination, seed dormancy, and seedling emergence, and to examine the main effects of seedling age, sand burial ratio, and their interactions on seedling biomass, shoot length, and root length (SPSS 11.0 for Windows). If the ANOVA showed significant treatment effects, Tukey's test was used to determine if differences between means were significant (Sokol and Rohlf 1995).

Table 2. Two-way analysis of variance for effects of different seed size, sand burial depth, and their interaction on seed germination, seed dormancy, and seedling emergence of Psammochloa villosa and Leymus secalinus.

\begin{tabular}{|c|c|c|c|c|c|c|}
\hline \multirow[b]{2}{*}{ Source of variance } & \multicolumn{3}{|c|}{ Psammochloa villosa } & \multicolumn{3}{|c|}{ Leymus secalinus } \\
\hline & df & $F$ value & $P$ value & df & $F$ value & $P$ value \\
\hline \multicolumn{7}{|l|}{ Seed germination } \\
\hline Seed size & 2 & 2.473 & 0.094 & 1 & 17.907 & $<0.001$ \\
\hline Sand burial depth & 5 & 364.805 & $<0.001$ & 5 & 51.818 & $<0.001$ \\
\hline Size $\times$ depth & 10 & 0.597 & 0.810 & 5 & 2.250 & 0.032 \\
\hline \multicolumn{7}{|l|}{ Seed dormancy } \\
\hline Seed size & 2 & 2.507 & 0.091 & 1 & 10.320 & 0.002 \\
\hline Sand burial depth & 5 & 662.071 & $<0.001$ & 5 & 49.552 & $<0.001$ \\
\hline Size $\times$ depth & 10 & 0.374 & 0.953 & 5 & 3.799 & 0.006 \\
\hline \multicolumn{7}{|l|}{ Seedling emergence } \\
\hline Seed size & 2 & 5.369 & 0.007 & 1 & 56.037 & $<0.001$ \\
\hline Sand burial depth & 5 & 178.339 & $<0.001$ & 5 & 263.172 & $<0.001$ \\
\hline Size $\times$ depth & 10 & 1.298 & 0.025 & 5 & 8.094 & $<0.001$ \\
\hline
\end{tabular}


(A) Psammochloa villosa

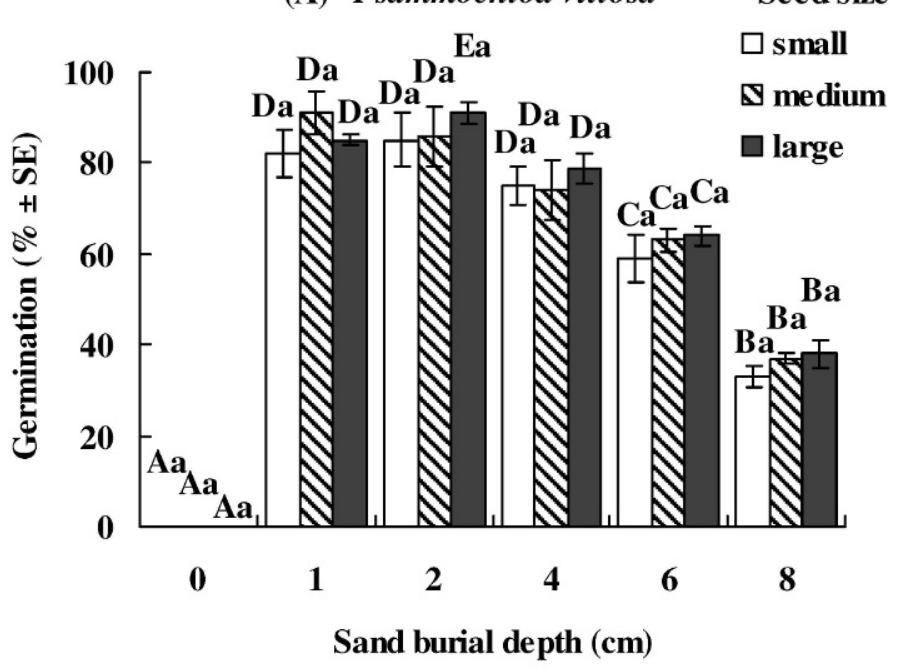

(B) Leymus secalinus

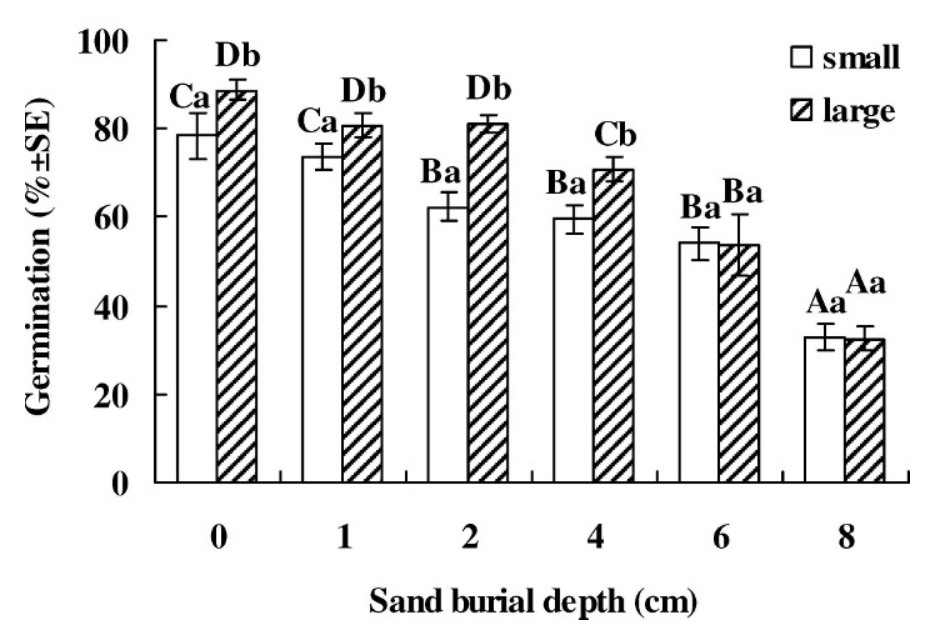

Figure 1. Effect of depth of burial in sand on germination of differentsized seeds of A, Psammochloa villosa and B, Leymus secalinus. Values in each group (small, medium, and large) followed by different lowercase letters and the values between burial depth groups followed by different uppercase letters are significantly different (Tukey's test, $P<0.05$ ).

\section{RESULTS}

Effect of Seed Size and Sand Burial on Seed Germination and Seedling Emergence

Seed germination (\%) of $P$. villosa and L. secalinus was affected significantly by sand burial depth (Table 2; Figs. 1A and $1 \mathrm{~B}$ ). Seeds of $P$. villosa on the sand surface did not germinate. Highest seed germination of $P$. villosa and $L$. secalinus was obtained at $1-2 \mathrm{~cm}$ and $0-1 \mathrm{~cm}$, respectively. In general, as sand burial depth increased, seed germination decreased. Seed germination of $P$. villosa was not affected by seed size or the interaction of seed size and sand burial (Fig. 1A; Table 2). However, seed germination of L. secalinus was affected significantly by seed size (Table 2 ). For L. secalinus, more seed germinated from large seeds than small seeds at 0-4$\mathrm{cm}$ burial depth (Fig. 1B). There was a significant effect of interaction of seed size and sand burial on seed germination of L. secalinus (Table 2).
(A) Psammochloa villosa

Seed size
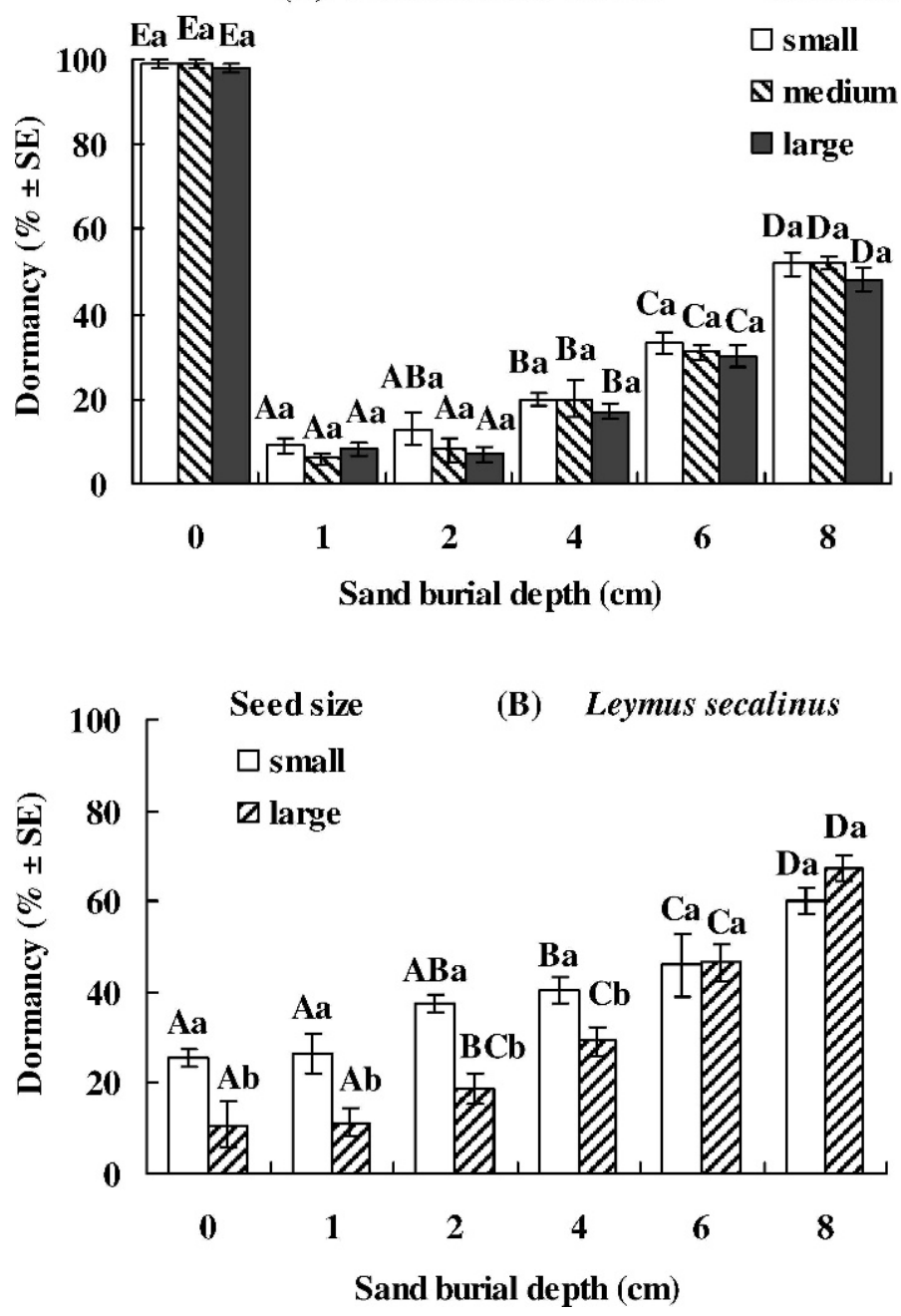

Figure 2. Effect of depth of burial in sand on seed dormancy of differentsized seeds of A, Psammochloa villosa and $\mathbf{B}$, Leymus secalinus. Values in each group followed by different lowercase letters and the values between burial depth groups followed by different uppercase letters are significantly different (Tukey's test, $P<0.05$ ).

Seed enforced dormancy (\%) of P. villosa and L. secalinus was affected significantly by sand burial depth (Figs. 2A and 2B). All seeds of $P$. villosa were in enforced dormancy on the sand surface. As sand burial depth increased from $1 \mathrm{~cm}$ to $8 \mathrm{~cm}$ and $0 \mathrm{~cm}$ to $6 \mathrm{~cm}$, seed dormancy of $P$. villosa and L. secalinus, respectively, increased. Seed-enforced dormancy of $P$. villosa was not affected by seed size or the interaction of seed size and sand burial (Table 2). However, seed dormancy of L. secalinus was affected significantly by seed size (Fig. 2B; Table 2). There was a significant effect between the interaction of seed size and sand burial on seed dormancy of L. secalinus (Table 2).

Seedling emergence (\%) of $P$. villosa was affected significantly by seed size, sand burial depth, and their interaction (Figs. 3A and 3B; Table 2). Highest seedling emergence of $P$. villosa was obtained at 1-2-cm depth; moreover, as burial depth increased seedling emergence decreased (Fig. 3A). More seedlings emerged from large seeds than from small seeds at depths of 2-8 cm (Fig. 3A). Seedling emergence of L. secalinus was also affected significantly by seed size, sand burial depth, and their interaction 


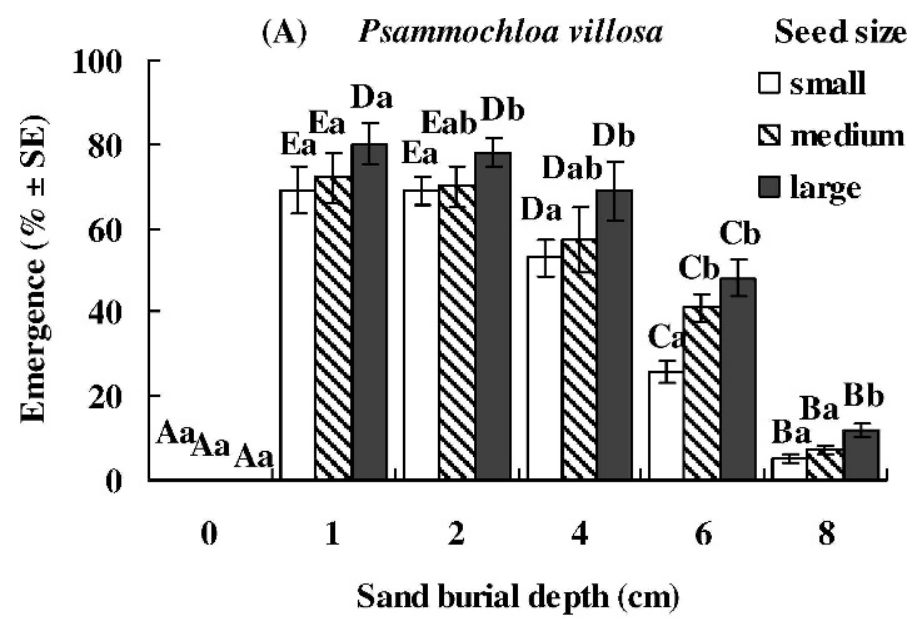

(A) Psammochloa villosa

Seedling age

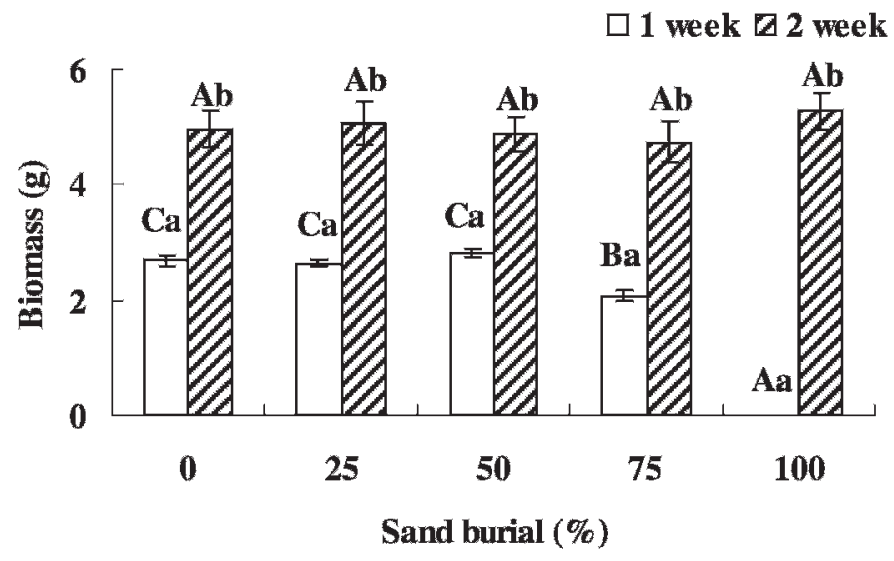

(B) Leymus secalinus

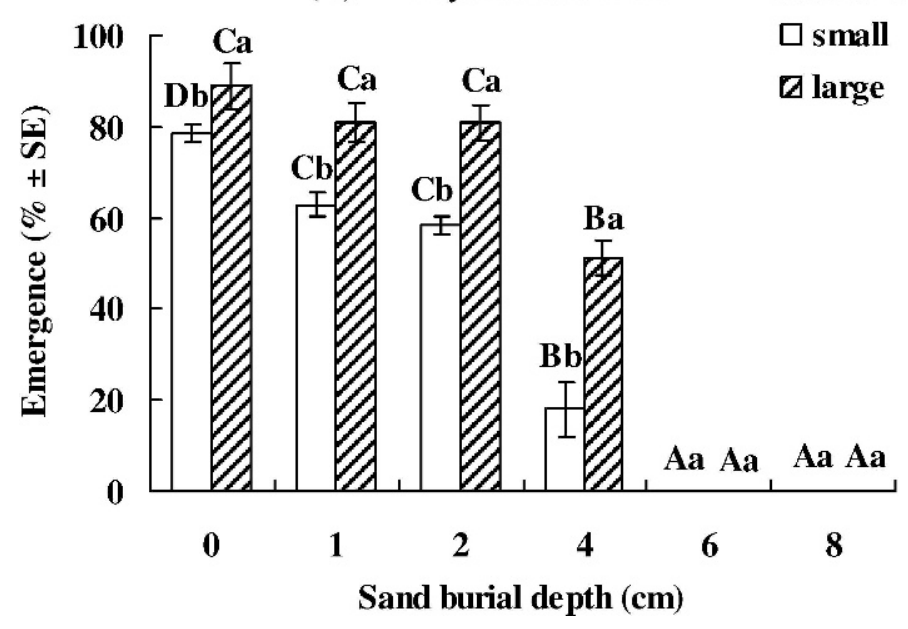

Figure 3. Effect of depth of burial in sand on seedling emergence from different sized seeds of A, Psammochloa villosa and B, Leymus secalinus. Values in each group followed by different lowercase letters and values between burial depth groups followed by different uppercase letters are significantly different (Tukey's test, $P<0.05$ ).

(Table 2). The highest germination percentage for L. secalinus was obtained at the sand surface. Large seeds buried at depths of $0-4 \mathrm{~cm}$ had greater seedling emergence than small seeds (Fig. 3B).

\section{Effect of Sand Burial on Seedling Growth}

After sand burial, seedling growth (biomass) of $P$. villosa was affected significantly by seedling age, sand burial ratio, and their interactions (Table 3). Two-week-old P. villosa seedlings were tolerant of total sand burial, whereas 1 -wk-old seedlings were only tolerant of $75 \%$ sand burial; the seedlings subject to $100 \%$ sand burial were decomposed. After $30 \mathrm{~d}$ of growth, the biomass of 2-wk-old seedlings was not affected by the burial ratio, whereas the biomass of 1 -wk-old seedlings was significantly affected by the sand burial ratio (Fig. 4A).

After sand burial, seedling biomass of $L$. secalinus was affected significantly by seedling age, sand burial ratio, and their interactions (Table 3). Both 1-wk-old and 2-wk-old $L$. secalinus seedlings were tolerant of only $75 \%$ sand burial, and the seedlings subject to $100 \%$ sand burial were decomposed.

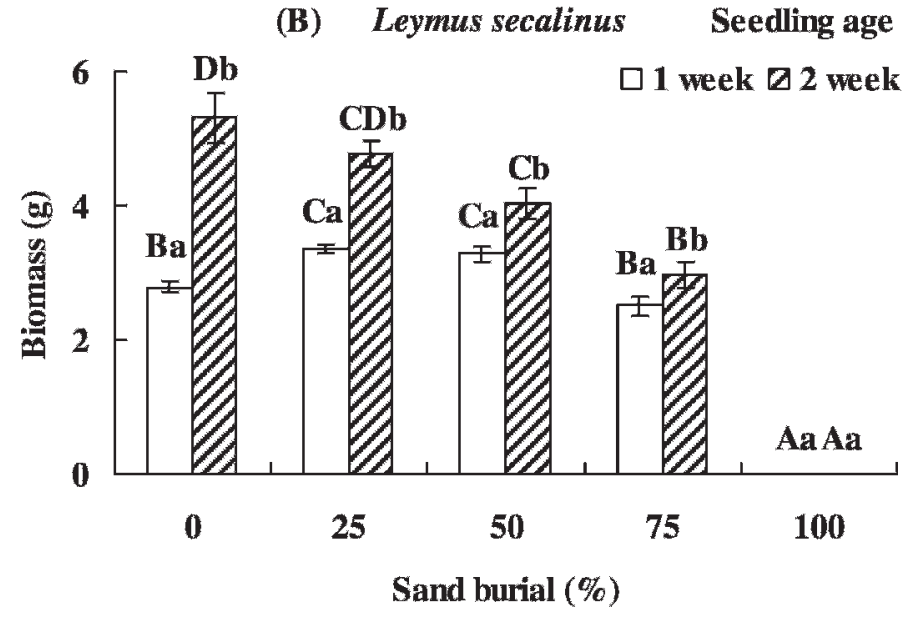

Figure 4. Effect of depth of burial on total biomass ( $g$, mean $\pm S E$ ) of A, Psammochloa villosa and B, Leymus secalinus seedlings. Values in each group followed by different lowercase letters and values between burial depth groups followed by different uppercase letters are significantly different (Tukey's test, $P<0.05$ ).

The biomass of 1 -wk-old $L$. secalinus seedlings increased by $25 \%$ and $50 \%$, but not $75 \%$ sand burial (Fig. 4B). However, as sand burial ratio increased, the biomass of 2 -wk-old seedlings of L. secalinus decreased (Fig. 4B).

Compared with the nonburied control, the shoot length of both 1-wk-old and 2-wk-old seedlings of $P$. villosa was significantly increased by the sand burial, whereas the root length of both 1-wk-old and 2-wk-old seedling was not affected (Fig. 5A). For L. secalinus, the shoot length of both 1-wk-old and 2 -wk-old seedling was decreased by $75 \%$ and $50-75 \%$ sand burial, respectively (Fig. 5B). The root length of 1-wk-old and 2-wk-old seedling of L. secalinus was not affected by sand burial (Fig. 5B).

\section{DISCUSSION}

What are the possible fates of seeds or seedlings after an episode of burial in sand dune habitats? Many seeds buried at shallow depths germinate and their seedlings emerge to the sand surface; however, as burial depth increases, some seeds still germinate but their seedlings are unable to emerge. Moreover, nongerminated 
Table 3. Two-way analysis of variance for effects of different seedling age, sand burial ratio, and their interaction on seedling biomass of Psammochloa villosa and Leymus secalinus.

\begin{tabular}{|c|c|c|c|c|c|}
\hline \multirow[b]{2}{*}{ Source of variance } & \multicolumn{3}{|c|}{ Psammochloa villosa } & \multicolumn{2}{|c|}{ Leymus secalinus } \\
\hline & df & $F$ value & $P$ value & $F$ value & $P$ value \\
\hline Seedling age & 1 & 6.037 & $<0.001$ & 84.912 & $<0.001$ \\
\hline Sand burial ratio & 4 & 6.037 & $<0.001$ & 192.198 & $<0.001$ \\
\hline Age $\times$ ratio & 4 & 9.675 & $<0.001$ & 15.630 & $<0.001$ \\
\hline
\end{tabular}

seeds buried deeply were in enforced dormancy, and formed a soil seedbank (Maun 1998; Huang et al. 2004a, 2004b). Seedlings of some plant species tolerate total sand burial, and their growth can accelerate with sand burial; however, other species cannot endure total sand burial (Maun 1994, 1998; Seliskar 1994; Yanful and Maun 1996; Zhang 1996).

Seed germination of P. villosa and of L. secalinus were affected significantly by sand burial. None of the $P$. villosa seeds germinated on the sand surface because of the strong evaporation rate and drought restriction (Huang et al. 2004a). On the contrary, a high percentage of seed germination of L. secalinus occurred on the sand surface, which might be due to the fact that its seeds have palea protection; this could help keep moisture for germination. However, roots of these seedlings failed to anchor into sand and thus the seedlings did not establish successfully. For both species, as burial depth increased to $>1 \mathrm{~cm}$, the percentage of seeds that germinated decreased; more seeds were in enforced dormancy. Many factors can affect seed germination after sand burial, and the possible reasons for enforced dormancy include poor soil aeration, high soil moisture, extremely low or high temperatures, and darkness (Maun 1998; Huang et al. 2004a, 2004b). The formation of a soil seedbank with dormant seeds
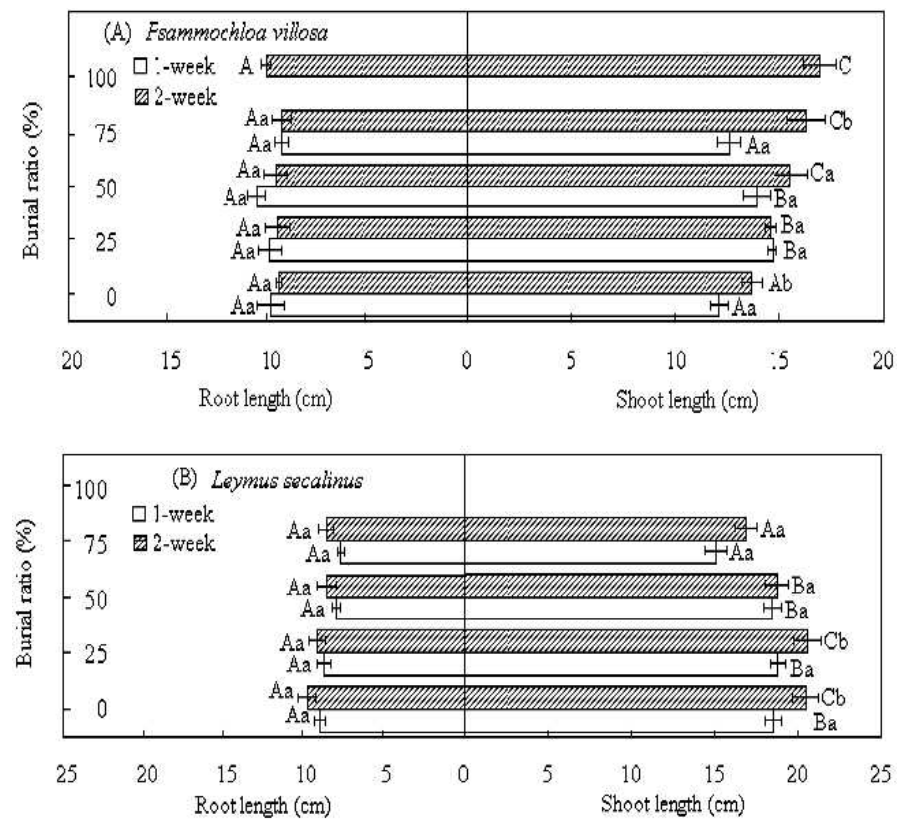

Figure 5. Effects of sand burial ratio on the length of shoots and roots of 1-wk-old and 2-wk-old seedlings of A, Psammochloa villosa and $\mathbf{B}$, Leymus secalinus. Values in each group followed by different lowercase letters and values between burial depth groups followed by different uppercase letters are significantly different (Tukey's test, $P<0.05$ ). benefits long-term survival of these species. Seeds in the soil seedbank could germinate later when sand erosion decreases sand burial depth (Baskin and Baskin 1998; Maun 1998). Germination of some plants is affected significantly by sand burial, e.g., Agropyron psammophilum J. M. Gillett \& H. Senn (Zhang and Maun 1990a), Leymus arenarius (L.) Hochst. (Greipsson and Davy 1995), Artemisia monosperma Delile (Huang and Gutterman 1998), Cirsium pitcheri (Torr. ex Eaton) Torr. \& A. Gray (Chen and Maun 1999), Artemisia ordosica Krasch. (Huang and Gutterman 2000), Artemisia sphaerocephala Krasch. (Huang and Gutterman 1999), Leymus racemosus (Lam.) Tzvel. (Huang et al. 2004b), and 10 species of Calligonum L. (Ren et al. 2002). However, for other species, such as Panicum virgatum $\mathrm{L}$. (Zhang and Maun 1990b) or Cakile edentula (Bigelow) Hook. (Zhang and Maun 1992), their seed germination was not affected by sand burial.

$P$. villosa seed germination is independent of seed size. There were no differences in the percentage germination of differentsized seeds from the same sand depths. However, the large seeds of $L$. secalinus had a greater rate of germination and thus less dormancy than small seeds at the same burial depth. Seed germination from different sizes of seeds showed different reactions to sand burial; this might influence seedling growth and thus population regeneration (Baskin and Baskin 1998; Gutterman 2000). Seedling emergence of these two grasses was negatively related to both sand burial depth and seed size. Emergence of these two grasses was increased by shallow sand burial, whereas it was restricted by deep sand burial. This phenomenon also was found on seedling emergence of some other sand dune plants, e.g., Leymus arenarius (Greipsson and Davy 1995) and 10 species of Calligonum (Ren et al. 2002). There are two possible factors that affect seedling emergence after seed germination: energy stored in seeds and sand burial depth (Maun 1998). In P. villosa and L. secalinus, seedlings from larger seeds emerged earlier and seedling emergence percentage was higher than from smaller seeds. Because the sand surface dries soon after a rain, seedlings that emerge earlier have a better chance of survival in the sand dune habitat. In deeper sand, some seedlings did not emerge, because seed mass was too low to support seedling growth to sand surface. Such a phenomenon also has been reported for Strophostyles helvola (L.) Elliott (Yanful and Maun 1996), Caragana microphylla Lam., and Hedysarum leave Maxim. (Zhu et al. 2004).

Different plants have different responses to sand burial; some psammophytes tolerate total burial, e.g., Ammophila breviligulata Fernald (Seliskar 1994), Elymus farctus (Viv.) Runemark ex Melderis (Harris and Davy 1987), and Strophostyles helvola (Yanful and Maun 1996), whereas other species can tolerate only partial burial, e.g., Agropyron psammophilum 
(Zhang and Maun 1990a), Cakile edentula (Bigelow) Hook. (Zhang 1996), Triplasis purpurea (Walter) Chapm. (Cheplick and Demetri 1999), Caragana microphylla (Zhu et al. 2004), and Hedysarum leave (Zhang et al. 2002). The re-emergence of seedlings from burial is determined by seedling age, relative burial depth, and amount of energy in the seedling that is available for growth (Maun 1994, 1998). Our results showed that seedling growths of $P$. villosa and $L$. secalinus have different responses to sand burial. For P. villosa, 1-wk-old and 2-wk-old seedlings could tolerate $75 \%$ and $100 \%$ sand burial, respectively, and the shoot elongation was enhanced by the burial. However, both 1-wk-old and 2-wk-old L. secalinus seedlings only tolerated $75 \%$ sand burial, and the growth of $L$. secalinus seedlings was inhibited by sand burial due to the decreased biomass and slow shoot elongation.

Enhanced seedling elongation after sand burial has important ecological advantages. Such elongation can cause an increase in leaf area and thus photosynthesis (Brown 1997). Tolerance to total sand burial might affect seedlings' survival and restrict species distributions to sand dune habitats. In Mu-Us sandy grassland, $P$. villosa mainly inhabits moving sand dunes in which it is often buried. L. secalinus, on the other hand, mainly inhabits meadows near rivers, where it is seldom buried. L. secalinus does not grow on moving sand dunes, and this might be due to intolerance of its seedlings to sand burial. Our results also suggested that lack of tolerance of seedlings of this species to total sand burial might restrict its distribution on sand dunes.

\section{MANAGEMENT IMPLICATIONS}

In summary, seed germination and seedling emergence of $P$. villosa and L. secalinus responded to sand burial in different ways. Seed germination of $P$. villosa was not affected by seed size; however, more seedlings from its large seeds can emerge to the sand surface after deeper burial $(>2 \mathrm{~cm})$. For L. secalinus, seed germination and seedling emergence of large seeds was higher than small seeds. Moreover, seedlings of $P$. villosa tolerate total sand burial, whereas seedlings of L. secalinus only tolerate partial sand burial. It is suggested that these differences of P. villosa and L. secalinus in seed germination and seedling growth might affect their natural distribution on different sand dunes with different degrees of sand burial.

These two grasses could be used in the restoration of degraded vegetation in $\mathrm{Mu}-\mathrm{Us}$ sandy grassland through airseeding because their seed germination and seedling growth were adapted to sand burial. It is better to choose large seeds of two grasses for air-seeding because they have a better chance for seedling emergence than smaller seeds after sand burial. $P$. villosa is suitable to moving sand dunes because its seedlings tolerate total sand burial; however, L. secalinus is more suitable to semifixed sand dunes because its seedlings only tolerate partial sand burial.

\section{ACKNOWLEDGMENTS}

Sincere thanks are extended to Jerry Baskin and Carol Baskin, Department of Biology, University of Kentucky, Lexington, USA, for critical review and perceptive comments on the manuscript, and for helping with the English.

\section{LITERATURE CITED}

BASKIN, C. C., AND J. M. BASKIN. 1998. Seeds. Ecology, biogeography, and evolution of dormancy and germination. San Diego, CA, USA: Academic Press. 666 p.

Bowers, J. E. 1996. Seedling emergence on Sonoran Desert dunes. Journal of Arid Environments 33:63-72.

BRown, J. F. 1997. Effects of experimental burial on survival, growth, and resource allocation of three species of dune plants. Journal of Ecology 85:151-158.

Chen, H., and M. A. Maun. 1999. Effects of sand burial depth on seed germination and seedling emergence of Circium pitcheri. Plant Ecology 140:53-60.

Cheplich, G. P., and H. Demetri. 1999. Impact of saltwater spray and sand deposition on coastal annual Triplasis purpurea (Poaceae). American Journal of Botany 86:703-710.

Dong, M. 1999. Effects of severing rhizome on clonal growth in rhizomatous grass species Psammochloa villosa and Leymus secalinus. Acta Botanica Sinica 41:194-198. [In Chinese with English abstract]

Dong, M., and B. Alaten. 1999. Clonal plasticity in response to rhizome serving and heterogeneous resource supply in the rhizomatous grass Psammochloa villosa in an Inner Mongolian dune, China. Plant Ecology 141:53-58.

Greipsson, S., And A. J. Davy. 1995. Seed mass and germination behavior in populations of the dune-building grass Leymus arenarius. Annals of Botany 76:493-501.

Gutterman, Y. 2000. Environmental factors and survival strategies of annual plant species in the Negev Desert, Israel. Plant Species Biology 15:113-125.

HarRIS, D., AND A. J. Davy. 1987. Seedling growth in Elymus farctus after episodes of burial with sand. Annals of Botany 60:587-593.

HeSP, P. A. 1991. Ecological processes and plant adaptations on coastal dunes. Journal of Arid Environments 21:165-191.

Huang, Z. Y., M. Dong, and Y. Gutterman. 2004a. Factors influencing seed dormancy and germination in sand, and seedling survival under desiccation, of Psammochloa villosa (Poaceae), inhabiting the moving sand dunes of Ordos, China. Plant and Soil 259:231-241.

Huang, Z. Y., M. Dong, and Y. Gutterman. 2004b. Caryopses dormancy, germination and seedling emergence in sand, of Leymus racemosus (Poaceae), a perennial sand dune grass inhabiting the Junggar Basin of Xinjiang, China. Australian Journal of Botany 52:519-528.

Huang, Z. Y., AND Y. GutTerman. 1998. Artemisia monosperma achene germination in sand: effects of sand depth, sand/moisture content, cyanobacterial sand crust and temperature. Journal of Arid Environments 38:27-43.

Huang, Z. Y., and Y. Gutterman. 1999. Influences of environmental factors on achene germination of Artemisia sphaerocephala, a dominant semi-shrub occurring in the sandy desert areas of Northwest China. South African Journal of Botany 65:187-196.

Huang, Z. Y., and Y. Gutterman. 2000. Comparison of germination strategies of Artemisia ordosica with its two congeners from deserts of China and Israel. Acta Botanica Sinica 42:71-80.

International Seed Testing Association. 1985. International rules for seed testing. Seed Science and Technology 13:299-355.

MA, Y. Q. 1994. Flora Intramongolica. Tomus 5. Huhhot, China: Inner Mongolia People's Press. 634 p. [In Chinese]

Martinez, M. L., and P. Moreno-Casasola. 1996. Effects of burial by sand on seedling growth and survival in six tropical sand dune species from the Gulf of Mexico. Journal of Coastal Research 12:406-419.

Maun, M. A. 1994. Adaptations enhancing survival and establishment of seedlings on coastal dune systems. Vegetatio 111:59-70.

Maun, M. A. 1998. Adaptations of plants to burial in coastal sand dunes. Canadian Journal of Botany 76:713-738.

Ren, J., L. TAO, And X. M. Liu. 2002. Effect of sand burial depth on seed germination and seedling emergence of Calligonum L. species. Journal of Arid Environments 51:603-611.

SeliskaR, D. M. 1994. The effects of accelerated sand accretion on growth, carbohydrate reserves, and ethylene production in Ammophila breviligulata (Poaceae). American Journal of Botany 81:536-541. 
Sokal, R. R., and F. J. Rohlf. 1995. Biometry. San Francisco, CA, USA: Freeman. $859 \mathrm{p}$.

Yanful, M., And M. A. Maun. 1996. Effects of burial of seeds and seedlings from different seed sizes on the emergence and growth of Strophostyles helvola. Canadian Journal of Botany 74:1322-1330.

Zhang, C. Y., F. H. Yu, and M. Dong. 2002. Effects of sand burial on the survival, growth and biomass allocation in semi-shrub Hedysarum laeve seedlings. Acta Botanica Sinica 44:337-343.

ZHANG, J. H. 1996. Interactive effects of soil nutrients, moisture and sand burial on the development, physiology, biomass and fitness of Cakile edentula. Annals of Botany 78:591-598.
Zhang, J. H., and M. A. Maun. 1990a. Effects of sand burial on seed germination, seedling emergence, survival, and growth of Agropyron psammophilum. Canadian Journal of Botany 68:304-310.

Zhang, J. H., And M. A. Maun. 1990b. Sand burial effects on seed germination, seedling emergence and establishment of Panicum virgatum. Holarctic Ecology 13:56-61.

Zhang, J. H., AND M. A. Maun. 1992. Effects of burial in sand on the growth and reproduction of Cakile edentula. Ecography 15:296-302.

Zhu, X. W., Z. Y. Huang, H. D. Liu, Y. Chu, S. M. Zhang, and M. Dong. 2004. Effects of burial in sand and seed size on seed germination and seedling emergence in two leguminous shrubs in the Otindag Sandland, China. Israel Journal of Plant Sciences 52:133-142. 